Al-Khwarizmi Engineering Journal,Vol. 12, No. 4, P.P. 72- 80 (2016)

Al-Khwarizmi

Engineering

Journal

\title{
Prediction of Surface Roughness and Material Removal Rate in Electrochemical Machining Using Taguchi Method
}

\author{
Abbas Fadhil Ibrahim \\ Department of Production and Metallurgy Engineering/ University of Technology \\ Email:abbasfadhel-2006@yahoo.com
}

(Received 31 January 2016; accepted 5 June 2016)

http://dx.doi.org/10.22153/kej.2016.06.001

\begin{abstract}
Electrochemical machining is one of the widely used non-conventional machining processes to machine complex and difficult shapes for electrically conducting materials, such as super alloys, Ti-alloys, alloy steel, tool steel and stainless steel. Use of optimal ECM process conditions can significantly reduce the ECM operating, tooling, and maintenance cost and can produce components with higher accuracy. This paper studies the effect of process parameters on surface roughness (Ra) and material removal rate (MRR), and the optimization of process conditions in ECM. Experiments were conducted based on Taguchi's L9 orthogonal array (OA) with three process parameters viz. current, electrolyte concentration, and inter-electrode gap. Signal-to-noise (S/N), the analysis of variance (ANOVA) was employed to find the optimal levels and to analyze the effect of electrochemical machining parameters on Ra and MRR. The surface roughness of the workpiece was decreased with the increase in current values and electrolyte concentration while causing an increase in material removal rate. The ability of the independent values to predict the dependent values $\left(\mathrm{R}^{2)}\right.$ were $87.5 \%$ and $96.3 \%$ for mean surface roughness and material removal rate, respectively.
\end{abstract}

Keyword: ECM, Carbon, MRR, , Ra, Taguchi Method.

\section{Introduction}

Electrochemical machining (ECM) is among the well recognized non-conventional manufacturing processes in industry. An electrical current passes through an electrolyte solution between an anode (workpiece) and a cathode (tool). The workpiece is eroded in accordance with Faraday's law of electrolysis [1].

Though, the principle of electrolysis was in use for a long time in a process called electroplating. But with certain modifications, ECM is often characterized as "reverse electroplating", with difference of no deposition of workpiece on cathode. In today's manufacturing era, machining process quality relies on surface finish of the machined workpiece to a great range. ECM contributed a lot to obtain good surface finish while machining. To enhance the machining performance, the precise selection of machining parameters is still a demanding job in ECM process as it is very difficult process involving so many unpredictable chemical reactions during machining. Various investigations have been carried out for improving the surface roughness (Ra) process characteristic of ECM process by numerous researchers [2]. Neto, J., et al. [3] took material removal rate (MRR), surface roughness (Ra) and over-cut as response parameters for studying process variables in electrochemical machining (ECM) of Valve-Steel. The surface roughness decreased with the increase in tool feed rate. Ganesan, G., et al. [4] used non-dominated sorting genetic algorithm-II (NSGA-II) to optimize the ECM process. Production rate was increased considerably by decreasing machining time. Chakradhar, D., and Gopal, A., [5] found tool feed rate as more influencing machining 
parameter by performing ANOVA in investigation and optimization of EN-31 steel, using grey relation analysis. Acharya, B.R., et al. [6] adopted Response Surface Methodology (RSM) to investigate the effect of four machining parameters, i.e., electric current, voltage, electrolyte flow rate and inter-electrode gap on MRR and surface roughness (SR). The surface roughness was influenced greatly by current. Goswami, R., et al. [7] reported the ECM of Mild Steel and Aluminium by using Taguchi method to analyze and predict the optimal process input parameters for material removal rate (MRR) and surface roughness (Ra). For both materials, current was the most significant machining parameter for surface roughness. Senthilkumar, et al. [8] developed a mathematical model in terms of machining process and studied the effect of various process parameters, such as electrolyte flow rate, electrolyte concentration, voltage and tool feed rate on the material removal rate and surface roughness Sathiyamoorthy, V., and Sekar, $T$. [9] used $\mathrm{NaCl}$ aqueous solution in electrochemical machining of die steel and three electrolyte jet patterns namely straight jet in circular, inclined jet in circular and straight jet in spiral to analyze the influence of electrolyte distribution on the surface roughness and material removal rate. Parameters for $\mathrm{Ra}$ and $\mathrm{MRR}$ prediction in ECM of LM25 Al/10\%SiCp composite.

In the past, various researchers have attempted to study and optimize ECM process by taking process input parameters, such as electric current, voltage, tool feed rate, electrolyte concentration, electrolyte flow rate, inter-electrode gap, etc. and analyzing their effect on response parameters viz. material removal rate, surface roughness, radial overcut etc., which decide the cutting performance. A very rare work has been done by taking work material as an input parameter for experimental study of ECM, as performance of process also be influenced by type of work material due to its chemical and electrical characteristics. In spite of other important input parameters, the workpiece material is one of the important parameter, which affects the surface roughness. As ECM is an atomic dissolution of work material involving chemical reactions during machining, so the chemical characteristics of work material affect the response parameters [2]. Taguchi Method (TM) was proposed by Genichi Taguchi, a Japanese quality management consultant. The aim of TM is to reduce the number of experiments to study the entire parameter space. The experimental results are then transformed into a signal-to-noise $(\mathrm{S} / \mathrm{N})$ ratio, a determination of quality characteristics deviating from or nearing to the desired values. There are three categories of quality characteristics in the analysis of the $\mathrm{S} / \mathrm{N}$ ratio, i.e., the nominal is the better, the higher is the better, and the lower is the better.

The equation used for calculating $\mathrm{S} / \mathrm{N}$ ratio for obtaining the smallest $\mathrm{Ra}$ is:

$$
S / N=-10 \log \left[\frac{1}{n} \sum_{i=1}^{n}\left(y_{i}^{2}\right)\right]
$$

The quality characteristic for material removal rate $(\mathrm{MRR})$ is of the-higher-the-better type. The equation used for calculating $\mathrm{S} / \mathrm{N}$ ratio for obtaining the largest MRR is::

$$
S / N=-10 \log _{10}\left[\frac{1}{n} \sum_{i=1}^{n}\left(1 / y_{i}^{2}\right)\right] ; i=1,2, \ldots n
$$

Where n: number of replications.

$y_{\mathrm{i}}$ : observed response value

In the current research work, an effort has been made to study the effect of input parameters on the surface roughness and material removal rate by selecting current with electrolyte concentration and inter-electrode gap as another two parameters and optimize these input parameters to improve $\mathrm{Ra}$ and MRR, using brass electrode and carbon steel (1020) anode in Taguchi method.

\section{Experimental Work}

The experimental setup includes an electrochemical machining unit and electrolyte tank. $\mathrm{NaCl}$ aqua solution was used as the electrolyte. The electrolyte is filled in the electrolyte tank and is supplied to the machining unit through an electrolyte pump. Brass tool has been used as an electrode as shown in Figure 1, and the electrolyte passes on the electrode. The ECM is shown in Figure 2. 


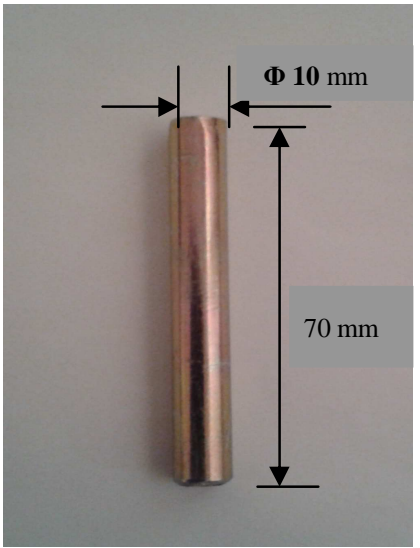

Fig. 1. Tool used in experimental work.

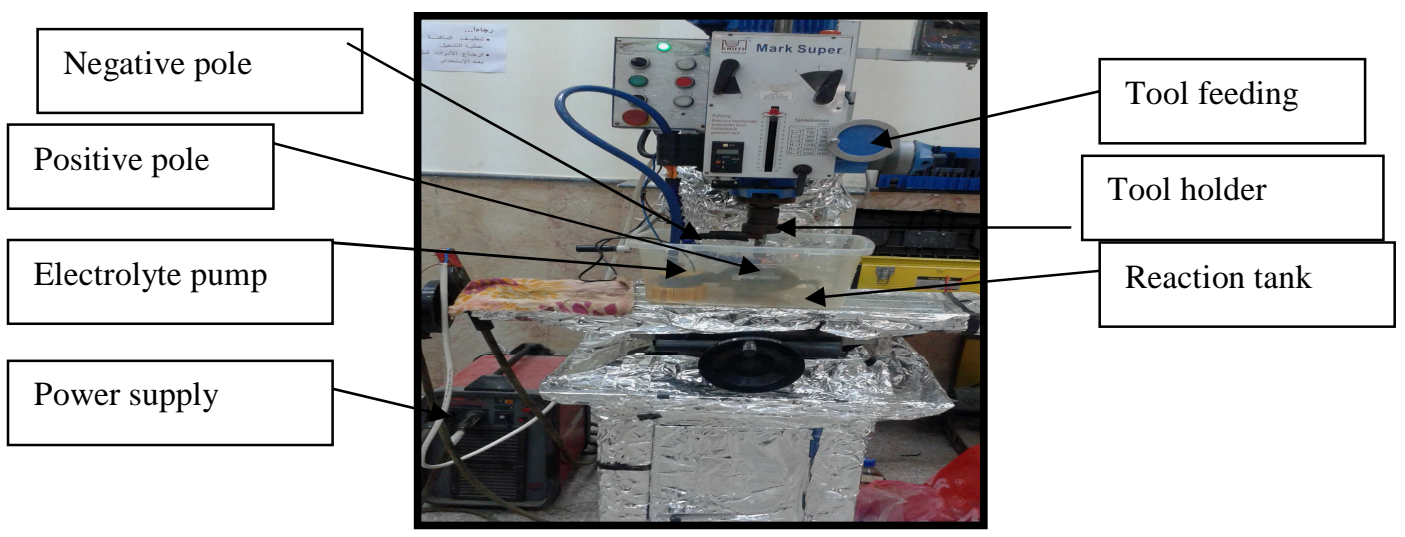

Fig. 2. Electrochemical machine.

The machining unit includes a spindle through which the electrode is inserted. The workpiece is fixed in a small vise and moved to the appropriate position using hand wheels. The maximum permissible current was set, and the inter electrode gap was accurately set by touching the electrode and then feeding the electrode in reverse direction for a specified time [11]. A tool of dia.8 $\mathrm{mm}$ was set throughout the experiments. The material to be used as tool or electrode should posses desirable properties, like easily machinable, low wear rate, good conductor of electricity and heat, cheap and readily available. In this experiment, brass was taken as (tool) electrode material at cathode. It is designed in circular shape so as to cut the cavity in workpiece in the similar profile. Then, the machining was done for the set values in Table 3. Carbon steel (1020) workpiece with a hardness of BHN 163 was used. The chemical compositions of tool and workpiece material are presented in Table.1. and Table.2., respectively, which were tested in Central Organization for Standardization and Quality Control . The experiments were conducted by setting different levels of parameters, and the results were recorded. The roughness measurement device was used to measure the roughness after every test to compare the results, and a weighing electronic machine with $\pm 1 \mathrm{mg}$ accuracy was used for measuring the material removal rate (MRR) in gram. The complete working environment of the experiments is shown inTable.3. 
Table 1,

Tool Material Composition (Brass).

\begin{tabular}{lcccccccccccc}
\hline Elements & $\mathbf{Z n}$ & $\mathbf{P b}$ & $\mathbf{S n}$ & $\mathbf{P}$ & $\mathbf{S i}$ & $\mathbf{S}$ & $\mathbf{A s}$ & $\mathbf{A g}$ & $\mathbf{B i}$ & $\mathbf{C d}$ & $\mathbf{S b}$ & $\mathbf{C u}$ \\
Weight\% & 35.5 & 1.7 & 0.157 & 0.006 & 0.002 & 0.009 & 0.008 & 0.004 & 0.006 & 0.004 & 0.03 & remain \\
\hline
\end{tabular}

Table 2,

Workpiece Material Composition (Carbon Steel 1020).

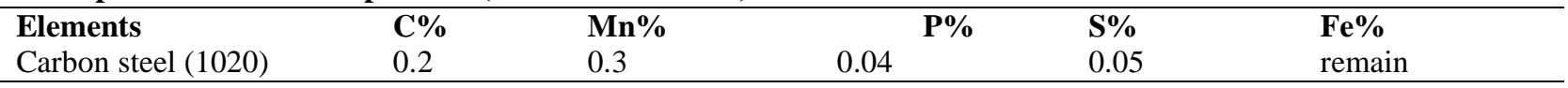

Table 3,

Input Factors of ECM.

\begin{tabular}{lccc}
\hline Factor & Current (Amp), A & Electrolyte concentration (g/l), B & Inter-electrode gap $(\mathbf{m m}), \mathbf{C}$ \\
\hline 1 & 50 & 75 & 0.5 \\
2 & 60 & 100 & 1 \\
3 & 70 & 125 & 1.5 \\
\hline
\end{tabular}

The experiments were conducted according to Taguchi analysis by using the machining set- up and the designed circular shaped electrodes. The control conditions, like applied voltage, feed rate, electrolyte concentration, and pressure, were varied to conduct nine different experiments and the weights of the workpieces were taken for calculation of material removal rate. MRR was calculated by the following formula as given: MRR = (initial weight-final weight $) /$ Time
During each drilling operation based on Taguchi L9 orthogonal array, the machining time was noted down. The weights of the workpieces were measured by the digital weighing machine before and after each operation. The standard Taguchi orthogonal array of L9 $\left(3^{4}\right)$ has been employed. Table (1) shows this array with cutting parameters used here in this research and combination of their levels for each experiment.

Table 4,

ECM Parameters According to Taguchi Method

\begin{tabular}{|c|c|c|c|c|c|c|c|c|c|c|c|}
\hline \multirow[t]{2}{*}{ No. } & \multicolumn{2}{|c|}{$\begin{array}{c}\text { Paramete } \\
\text { rs coded }\end{array}$} & \multicolumn{3}{|c|}{ Parameters of ECM } & \multirow{2}{*}{$\begin{array}{c}\mathbf{R a} \\
\text { measured } \\
(\mu \mathrm{m})\end{array}$} & \multirow{2}{*}{$\begin{array}{c}\mathbf{R a} \\
\text { predicted } \\
(\mu \mathrm{m})\end{array}$} & \multirow{2}{*}{$\begin{array}{c}\text { MRR } \\
\text { measured } \\
(\mathrm{gm} / \mathrm{sec})\end{array}$} & \multirow{2}{*}{\begin{tabular}{l}
\multicolumn{1}{c}{ MRR } \\
predicted \\
(gm/sec)
\end{tabular}} & \multirow{2}{*}{$\begin{array}{l}\mathrm{S} / \mathbf{N} \\
\text { for } \\
\text { Ra }\end{array}$} & \multirow{2}{*}{$\begin{array}{l}\text { S/N } \\
\text { for } \\
\text { MRR }\end{array}$} \\
\hline & A & C & $\begin{array}{l}\text { Curren } \\
\mathrm{t} \text { (amp) }\end{array}$ & $\begin{array}{l}\text { Electrolyte } \\
\text { conc. }(\mathrm{g} / \mathrm{l})\end{array}$ & $\begin{array}{c}\text { IEG } \\
(\mathbf{m m})\end{array}$ & & & & & & \\
\hline 1 & 1 & 1 & 30 & 75 & 0.5 & 2.07 & 2.0956 & 0.0146 & 0.0139 & -6.32 & 36.71 \\
\hline 2 & 1 & 2 & 30 & 100 & 1 & 2.34 & 2.1556 & 0.0139 & 0.0143 & -7.38 & 37.13 \\
\hline 3 & 1 & 3 & 30 & 125 & 1.5 & 2.36 & 2.5189 & 0.0113 & 0.0117 & -7.46 & 38.94 \\
\hline 4 & 2 & 2 & 50 & 75 & 1 & 2.23 & 2.3889 & 0.0122 & 0.0126 & -6.96 & 38.27 \\
\hline 5 & 2 & 3 & 50 & 100 & 1.5 & 2.86 & 2.8856 & 0.0110 & 0.0103 & -9.13 & 39.17 \\
\hline 6 & 2 & 1 & 50 & 125 & 0.5 & 2.03 & 1.8456 & 0.0135 & 0.0139 & -6.15 & 37.39 \\
\hline 7 & 3 & 3 & 70 & 75 & 1.5 & 3.12 & 2.9356 & 0.0141 & 0.0145 & -9.88 & 37.02 \\
\hline 8 & 3 & 1 & 70 & 100 & 0.5 & 1.87 & 2.0289 & 0.0180 & 0.0184 & -5.44 & 34.89 \\
\hline 9 & 3 & 2 & 70 & 125 & 1 & 1.93 & 1.9556 & 0.0191 & 0.0184 & -5.71 & 34.38 \\
\hline
\end{tabular}

\section{Results and Discussion}

As illustrated in Figure 3, the comparison of the experimental data and the model reveals that the prediction is satisfactory for surface roughness. Surface roughness for each experiment is measured using portable surface finish tester, the regarding between measured and predicted material removal rate as shown in Figure 6 , it is clear there is an agreement in more points between two bar charts, this shows the efficiency Taguchi method to predict the variables. The ability of the independent values to predict the dependent values) $\mathrm{R}^{2}$ pieces is $87.5 \%$ and $96.3 \%$ for mean surface roughness and material removal 
rate respectively The average (mean) of these characteristics and $\mathrm{S} / \mathrm{N}$ ratio (in decibels) is shown for each characteristic.. To investigate the designed conditions and to indicate the conditions is the main purpose of used the analysis of variance (ANOVA), which significantly affect the quality characteristic. This analysis helps to find out the relative contribution of finishing parameter in controlling the response of the ECM process. In the analysis, the summation of the square deviation is calculated from the value of $\mathrm{S} / \mathrm{N}$ ratio by separating the total variability of $\mathrm{S} / \mathrm{N}$ ratio for each control parameter. The "P\%" value in Tables (5 and 6) shows the effectiveness of each condition toward affecting the related response characteristics within the limited range. From Table (5), it is concluded that the current (parameter A) is the most significant parameter for minimum surface roughness, and the electrolyte concentration (parameter B) is the next significant parameter for minimum Ra. Figures (4 and 5) shows the plot of the means of the surface roughness and the means of $\mathrm{S} / \mathrm{N}$ ratio .
In the Figures it is concluded that the optimal parametric combination for minimum surface roughness is $\mathrm{A} 1 \mathrm{~B} 3 \mathrm{C} 1$, i.e., at $30 \mathrm{amp}$ current, $125 \mathrm{~g} / 1$ electrolyte concentration and $0.5 \mathrm{~mm}$ inter-electrode gap. The lowest surface roughness height $\mathrm{Ra}$ was suggested that the parametric combination within the considered range as mentioned above gives. From Table (6), it is concluded that the electrolyte concentration (parameter B) is the most significant parameter for maximum MRR, inter-electrode gap (parameter C) is the next significant parameter for maximum MRR. Figures (7 and 8) shows shows the plot of the means of the material removal rate and the means of $\mathrm{S} / \mathrm{N}$ ratio. The optimal parametric for maximum material removal rate is A3 B3 C1, i.e., at $70 \mathrm{amp}$ current, $125 \mathrm{~g} / \mathrm{l}$ electrolyte concentration and $0.5 \mathrm{~mm}$ interelectrode gap. The minimum quantity of the tool metal removed is considered as an indicator that the tool life will be longer at these levels combinations of cutting conditions.

Table 5,

Analysis of Variance for Means (Ra).

\begin{tabular}{lllllll}
\hline Source & DF & Seq.SS & Adj.SS & Adj.MS & F & P \\
\hline A & 2 & 0.02056 & 0.02056 & 0.01028 & 0.11 & 0.897 \\
B & 2 & 0.21056 & 0.21056 & 0.10528 & 1.17 & 0.461 \\
C & 2 & 1.03149 & 1.03149 & 0.51574 & 5.74 & 0.148 \\
Residual error & 2 & 0.17976 & 0.17976 & 0.08988 & $/$ & $/$ \\
Total & 8 & 1.44236 & $/$ & $/$ & $/$ & $/$ \\
\hline
\end{tabular}

Table 6,

Analysis of Variance for Means (MRR).

\begin{tabular}{lllllll}
\hline Source & DF & Seq.SS & Adj.SS & Adj.MS & F & P \\
\hline A & 2 & 0.000039 & 0.000039 & 0.000019 & 17.08 & 0.055 \\
B & 2 & 0.000002 & 0.000002 & 0.000001 & 0.68 & 0.594 \\
C & 2 & 0.000019 & 0.000019 & 0.000010 & 8.42 & 0.106 \\
Residual error & 2 & 0.000002 & 0.000002 & 0.000001 & $/$ & $/$ \\
Total & 8 & 0.000062 & $/$ & $/$ & $/$ & $/$ \\
\hline
\end{tabular}

(DF=Degree of Freedom, SS=Sum of Square, MS=Mean of Square, P=Percent of contribution) 


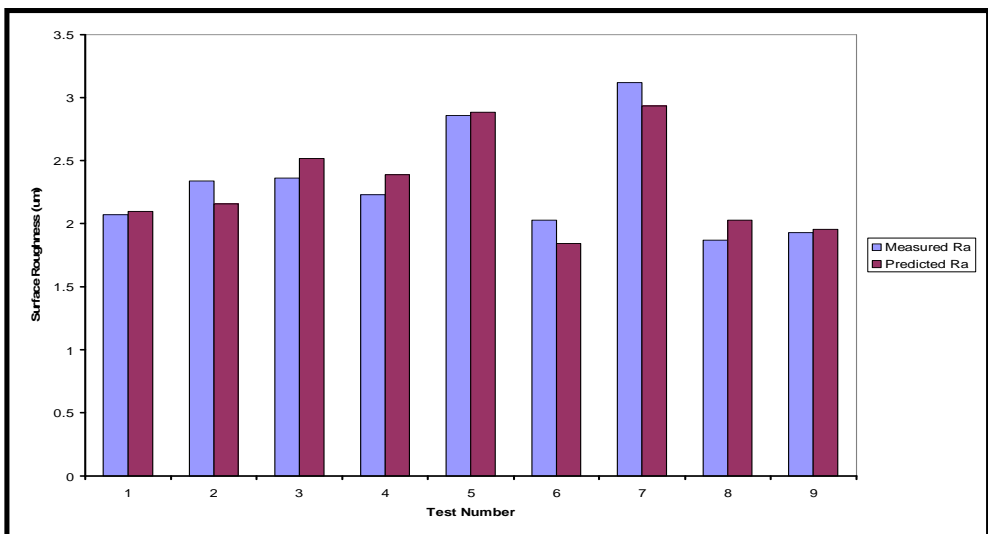

Fig. 3. The diagram of the measured and predicted surface roughness for the experimental data.

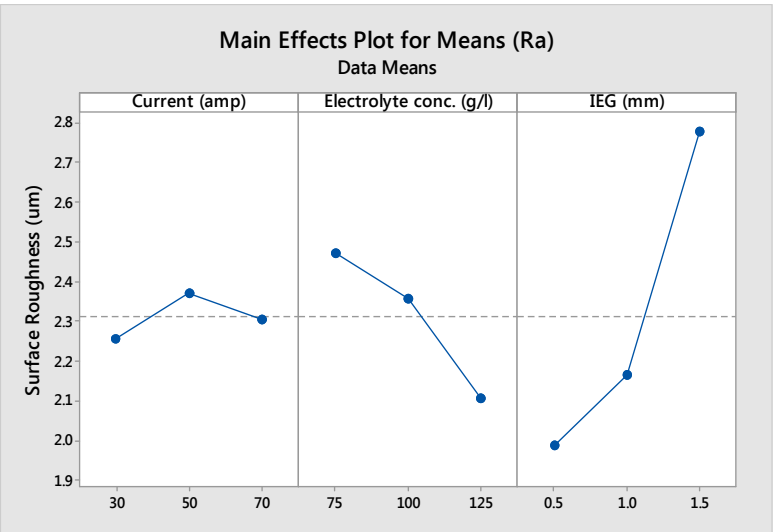

Fig. 4. Main effects Plot for means (Ra)

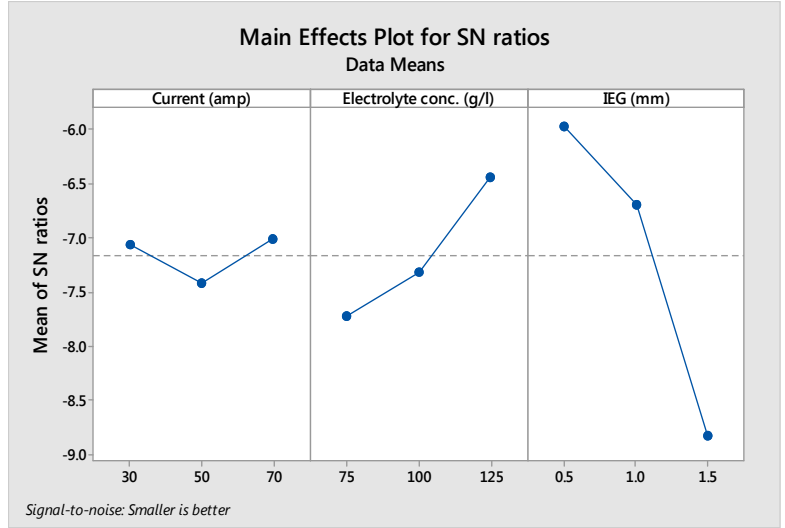

Fig. 5. The mean $\mathrm{S} / \mathrm{N}$ ratio plot for $(\mathrm{Ra})$.

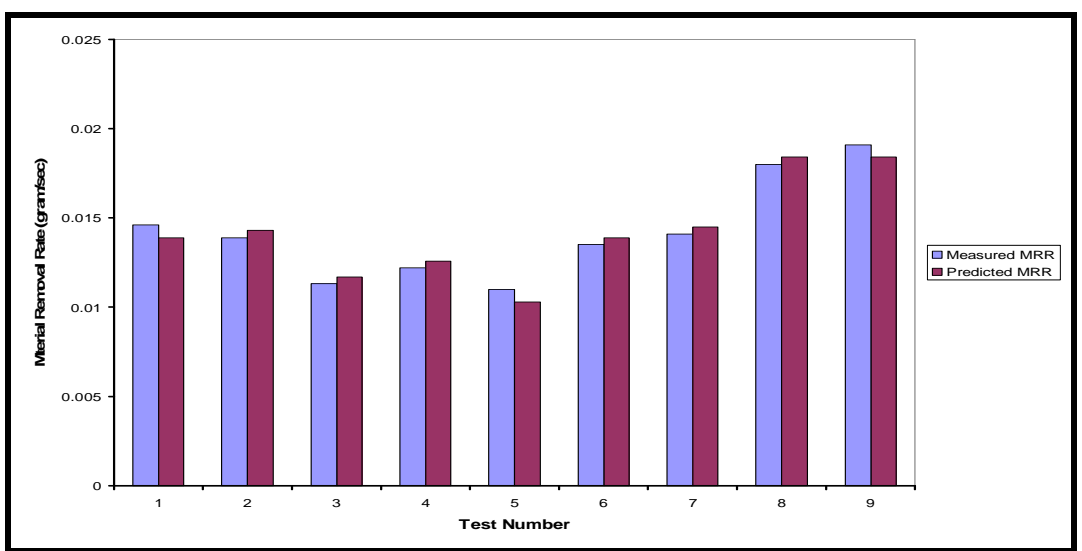

Fig. 6. The diagram of the measured and predicted material removal rate for the experimental data. 


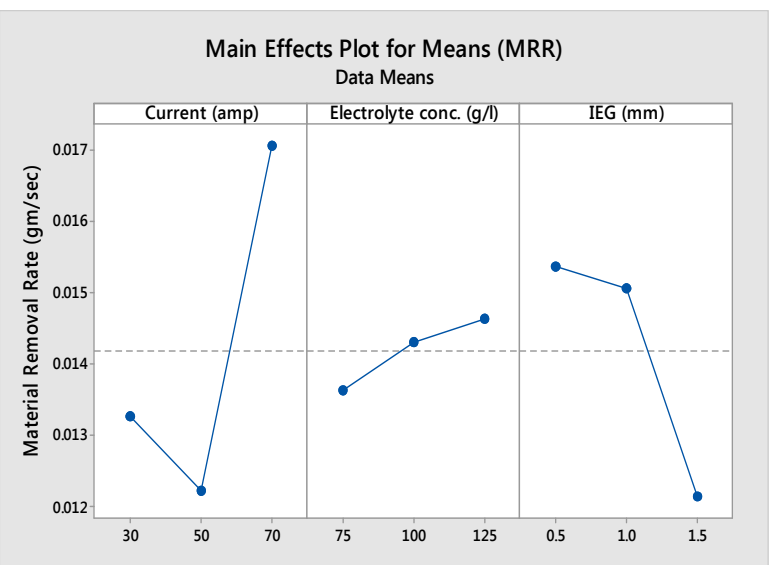

Fig. 7. Main effects Plot for means (MRR).

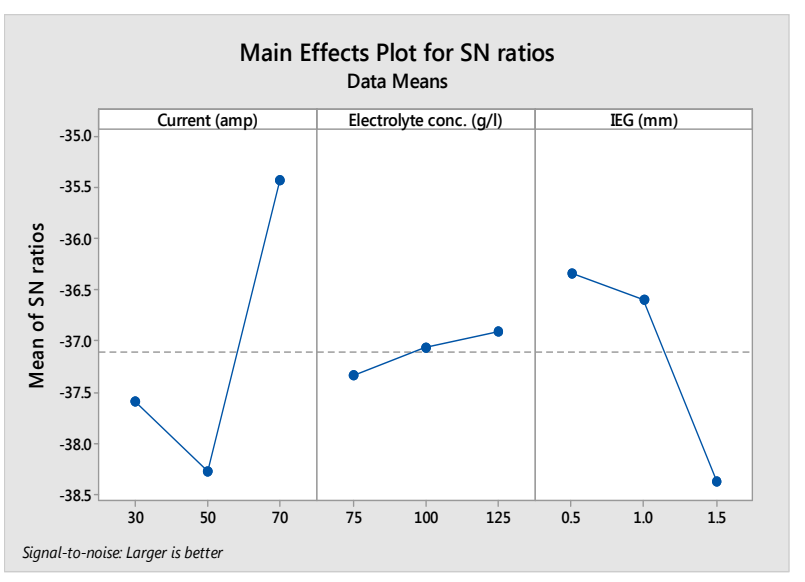

Fig. 8. The mean $\mathrm{S} / \mathrm{N}$ ratio plot for (MRR).

\section{Conclusions}

From the present work the major conclusions which can be deduced can be summarized as follows:

1- The ability of the independent values to predict the dependent values $\mathrm{R}^{2}$ pieces are $87.5 \%$ and $96.3 \%$ for mean surface roughness and material removal rate, respectively.

2- The current (parameter A) is the most significant parameter, and the electrolyte concentration (parameter B) is next significant parameter for minimum Ra.

3- For minimum surface roughness the optimal parametric combination is $\mathrm{A} 1 \mathrm{~B} 3 \mathrm{C} 1$, i.e., at 30 amp current, $125 \mathrm{~g} / \mathrm{l}$ electrolyte concentration and $0.5 \mathrm{~mm}$ inter-electrode gap.

4- The electrolyte concentration (parameter B) is the most significant parameter, and the interelectrode gap (parameter C) is next significant parameter for maximum MRR.

5- The optimal parametric for maximum material removal rate is $\mathrm{A} 3 \mathrm{~B} 3 \mathrm{C} 1$, i.e., at $70 \mathrm{amp}$ current, $125 \mathrm{~g} / 1$ electrolyte concentration and $0.5 \mathrm{~mm}$ inter-electrode gap.

6- The surface roughness of the workpiece is decreasing with increasing in current values, while the material removal rate is increasing.

7- The surface roughness of the workpiece is increasing with increasing inter-electrode gap while causing a decrease in material removal rate.

8- Increasing the electrolyte concentration causes decreasing of surface roughness and increasing material removal rate.

\section{References}

[1] Milan Kumar Das, Kaushik Kumar, Tapan Kr. Barman and Prasanta Sahoo ,'Optimization of Surface Roughness and MRR in Electrochemical Machining of EN31 Tool Steel using Grey-Taguchi Approach", Procedia Materials Science 6,PP. 729 - 740, 2014.

[2] Ramandeep Singh, Nikhil Gandotra and Ayyappan Solaiyappan, "Study of Different Work Materials Effect on Surface Roughnes in Electrochemical Machining Process", International Journal of Research in Engineering and Technology; Vol. 04 Issue: 07, PP. 505-513,2015.

[3] Neto, J., Silva, E., and Silva, M., "Intervening Variables in Electrochemical Machining"; Journal of Materials Processing Technology, Vol. 179, pp. 92-96, 2006.

[4] Ganesan, G., Senthilkumar, C., and Karthikeyan, R.., "Parametric Optimization of Electrochemical Machining of $\mathrm{Al} / 15 \%$ SiCp Composites Using NSGA-II," Transaction of Nonferrous Metal Society of China, Vol. 21, pp. 2294-2300, 2011.

[5] Chakradhar, D., and Gopal, A., "MultiObjective Optimization of Electrochemical Machining of EN31 Steel by Grey Relational Analysis" ,International Journal of Modeling and Optimization, Vol. 1, No. 2, pp. 113 117, 2011

[6] Acharya, B., Mohanty, C., and Mahapatra, S., "Multi-objective Optimization of 
[7] Electrochemical Machining of Hardened Steel Using NSGA-II", Procedia Engineering, Vol. 51, pp. 554-560, 2013.

[8] Goswami, R., Chouhan, R., and Chaturvedi, V., "The implementation of Taguchi Approach on ECM Process Parameters for Mild Steel and Aluminium" ,International Journal of Research in Engineering \& Applied Sciences, Vol. 3, pp. 53 - 62, 2013.

[9] Senthilkumar, C., Ganesana, G., Karthikeyan, R., "Influence of Input Parameter on Characteristics of ElectroChemical Machining Process", International Journal Applie Science and Engineering 11, pp.13-24, 2013.

[10] Sathiyamoorthy, V., and Sekar, T., "Experimental Studies on Improving the Performance of Electrochemical Machining of High Carbon, High Chromium Die Steel Using Jet Patterns", Carbon -Science and Technology, Vol. 6, pp. 321 - 329, 2014.

[11] Hocheng H., Sun Y.H., Lin S.C., Kao P.S. , "A Material Removal Analysis of Electrochemical Machining Using Flat-end Cathode", Journal of Materials Processing Technology 140 ,pp. 264-268, 2003.

[12] Jadhav P.V., Bilgi D.S., Sumit Sharan, and Rachit Shrivastava, "Experimental Investigation on MRR of Pulse Electrochemical machining (PECM) based on Taguchi Method", IJIRSET Vol. 3, Issue 1, PP. 8800-8809, 2014. 


\title{
التنبؤ بالخثونة السطحية ومعدل ازالة المادة في التشغيل الكهروكيميائي بأستخدام طريقة تاكوجي
}

\author{
عباس فاضل ابر اهيم

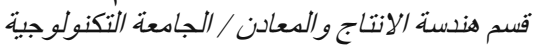 \\ البريد الاكتكروني: yahoo.com abbasfadhel_2006@
}

تعتبر عملية التشغيل الكهروكيميائي واحدة من عمليات التشغيل اللاتقليدي لتشغيل الاشكال المعقدة للمواد ذات التوصيل الكهربائي صعبة التشغيل كسبائك

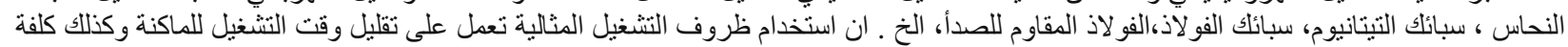

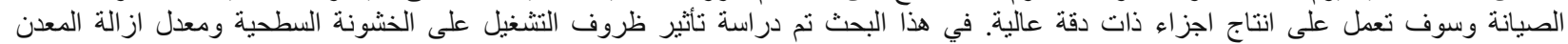

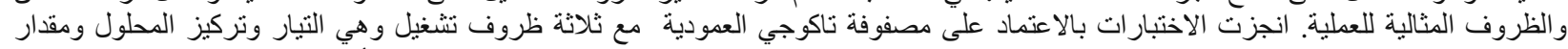

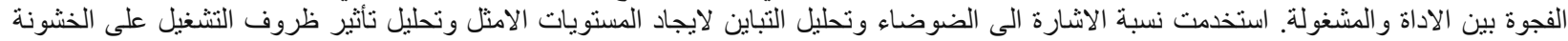

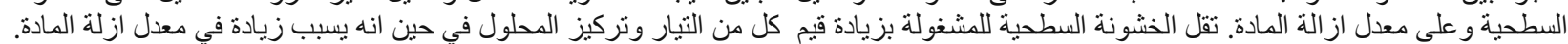

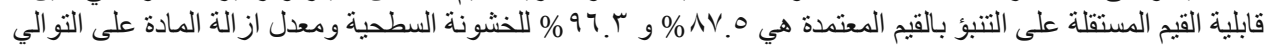

